\title{
Dermatologist and Patient Preferences in Choosing Treatments for Moderate to Severe Psoriasis
}

\author{
Matthew Alcusky · Seina Lee · Gordon Lau - Gretchen R. Chiu • \\ Nandini Hadker · Aparna Deshpande · Stephen Fleming • \\ Nicola Vance · Steve Fakharzadeh
}

Received: August 23, 2017 / Published online: October 20, 2017

(C) The Author(s) 2017. This article is an open access publication

\begin{abstract}
Introduction: The objective of the study was to determine the relative importance (RI) of treatment attributes psoriasis patients and physicians consider when choosing between biologic therapies based on psoriasis severity.

Methods: A discrete choice experiment (DCE) weighting preference for eight sets of hypothetical treatments for moderate or severe psoriasis was conducted. DCE hypothetical treatments were defined and varied on combinations of efficacy, safety, and dosing attributes [frequency/setting/route of administration (ROA)].

Results: When assuming moderate psoriasis in the patient DCE, ROA (RI 29\%) and efficacy (RI $27 \%$ ) drive treatment choices. When assuming severe disease in the DCE, patients preferred treatments with higher efficacy (RI 36\%); ROA
\end{abstract}

Enhanced content To view enhanced content for this article go to www.medengine.com/Redeem/03CCF060 2B715C45.

M. Alcusky

UMass Memorial Medical Center University

Campus, Worcester, MA, USA

S. Lee $\cdot$ S. Fakharzadeh

Janssen Scientific Affairs, LLC, Horsham, PA, USA

G. Lau $(\varangle)$. G. R. Chiu · N. Hadker .

A. Deshpande $\cdot$ S. Fleming $\cdot$ N. Vance

Trinity Partners, Waltham, MA, USA

e-mail: glau@trinitypartners.com was relatively less important (RI 15\%). From the physician perspective, ROA (RI 32\%) and efficacy (RI 26\%) were most important for moderate psoriasis patients. In the physician model for severe psoriasis, efficacy (RI 42\%) was the predominant driver followed by ROA (RI 22\%). Regardless of severity, probability of loss of response within 1 year was the least important factor.

Conclusions: The severity of disease is a critical element in psoriasis treatment selection. There are high levels of alignment between physicianand patient-derived preferences in biologic treatment choice selection for psoriasis.

Funding: Janssen Pharmaceuticals.

Keywords: Biologic treatment selection; Discrete choice experiment; Moderate severe psoriasis; Patients and physician DCE

\section{INTRODUCTION}

Psoriasis is a chronic, systemic, autoimmune disease that affects the skin and may be associated with other inflammatory conditions and comorbidities. The prevalence of diagnosed psoriasis has previously been estimated to range from $0.5 \%$ to $3.15 \%$ of the adult population in the USA, with the most common form being plaque psoriasis [1-5]. The burden of psoriasis is substantial, with negative physical, emotional, and psychosocial implications for patients' 
quality of life [6]. This burden is particularly large among adults with moderate to severe disease, a subgroup representing approximately $18 \%$ of the overall psoriasis population [1]. The sizeable disease burden in moderate to severe psoriasis is reflected in the incremental annual total healthcare $(\$ 18,960$ per patient), medical $(\$ 13,990$ per patient), and pharmacy (\$3895 per patient) expenditures for this population [7].

The treatment paradigm for psoriasis has evolved with the emergence of biologic therapies targeting specific cytokines in the inflammatory cascade driving disease pathogenesis. Current therapeutic strategies vary by disease severity and other patient-specific factors, with available treatments comprising topical therapies, phototherapies, and systemic agents, which include conventional and newer oral agents, as well as biologics that can be administered through subcutaneous injection (subQ) or intravenous infusion (IV) [8]. Clinical trial data suggest superior efficacy with biologic agents compared with conventional systemic agents [9]; long-term observational data indicate a consistent and reassuring safety profile based on the collective body of evidence to date compared with conventional systemic medications [10].

Despite improved efficacy, safety profile, and adherence to therapy among patients on biologics compared to those on systemic therapies [9], utilization of biologic agents remains low. A 2012 survey found that only $8 \%$ of moderate to severe psoriasis patients reported use of biologic therapy while dermatologists estimated that about $36 \%$ of this patient population was treated with biologics. These findings suggest that there are discordant perceptions of disease severity and underutilization of dermatologist services by moderate to severe patients. Furthermore, $31 \%$ of moderate to severe psoriasis patients reported that their primary goals of treatment were not met by their current treatment [11]. Several reasons for underutilization of biologics have been cited by physicians, including managed care utilization controls, unaffordable out-of-pocket costs for patients, and perceived lack of adequate long-term safety data by prescribers.
Psoriasis assessments (e.g., PGA, PASI) tend to be physician-centric, which may further obscure patients' perception of disease burden and preferred treatment attributes. Furthermore, differences in how patients and physicians evaluate benefits and risks of therapies emphasize the importance of shared decision-making when selecting a psoriasis treatment $[12,13]$. Shared decision-making has been shown to beneficially influence patient satisfaction, treatment compliance, and ultimately health outcomes [14-17].

Further studies are needed to better understand physician and patient preferences around choice of therapy. Discrete choice experiments (DCE) are used to quantify preferences for therapies or services where various elements may limit choices. DCEs have been used for this purpose in a broad range of therapeutic areas in health care. The choice task requires respondents to make trade-offs (akin to real-world decision-making) between various treatment attributes and levels in determining their overall treatment preferences. Previous DCEs in psoriasis have evaluated either physician [17] or patient [18-20] preferences for treatment attributes, without direct comparison between stakeholders. In this study, the relative importance of clinical attributes of biologics and novel oral therapies that dermatologists and psoriasis patients consider in choosing treatments are quantified, and similarities and differences in attribute prioritization by dermatologists and patients are compared.

\section{METHODS}

\section{Survey Instruments}

To address the objectives of this study, we developed physician and patient survey instruments using DCE methodology. The physician and patient survey instruments had parallel designs to allow for comparison of treatment attributes across the stakeholders. In addition to the DCE, the surveys collected data on respondent demographics, stated preferences for psoriasis treatments, the impact of physician-patient relationship on therapy choice, as 
well as physician and patient attitudes towards aspects of treatment decisions. Each survey instrument took approximately $30 \mathrm{~min}$ to complete.

Stated importance was measured on a Likert scale of $1-9$, with a score of 1 representing not at all important and a score of 9 representing extremely important. The scale was set to 9 points to allow for more gradation in ratings of attribute importance to discern differences between choices.

To enhance comprehension and to establish a consistent baseline of disease severity, the patient survey included reference pictures showing a visual representation of body surface area (BSA) affected by psoriasis (Fig. 1).

Both the physician and patient survey instruments and treatment choice sets were submitted to the University of Mississippi's Institutional Review Board (IRB), which determined the study to be exempt from review. The surveys were also pretested with two dermatologists and one patient with psoriasis to ensure the relevance of the content, comprehensiveness of response options, and user-friendliness of the survey. All procedures followed were in accordance with the ethical standards of the responsible committee on human experimentation (institutional and national) and with the Helsinki Declaration of 1964, as revised in 2013.

\section{Discrete Choice Experiment}

Two separate DCE surveys, each containing a series of eight treatment choice questions, were used for patients with either moderate or severe psoriasis. Each choice set had three hypothetical treatments with varying levels within attributes from which respondents selected. Dermatologists and patients with moderate or severe psoriasis were asked to choose which of the three treatments they would select to treat moderate psoriasis and then which of the three they would select to treat severe psoriasis on the basis of the attributes provided in the survey for each hypothetical therapy.

The design and analysis of this study followed published DCE guidelines $[17,18]$.

\section{Attributes and Levels Tested in DCE}

Package inserts, clinical literature, and consultation with key opinion leaders (KOLs) informed the choice of attributes and levels for each attribute for hypothetical treatments. Efficacy and safety data for current and developing biologic treatments for psoriasis were used to design the attributes and levels tested in the DCE. Specific attributes consisted of probability of improvement in psoriasis plaques as measured by the psoriasis area severity index

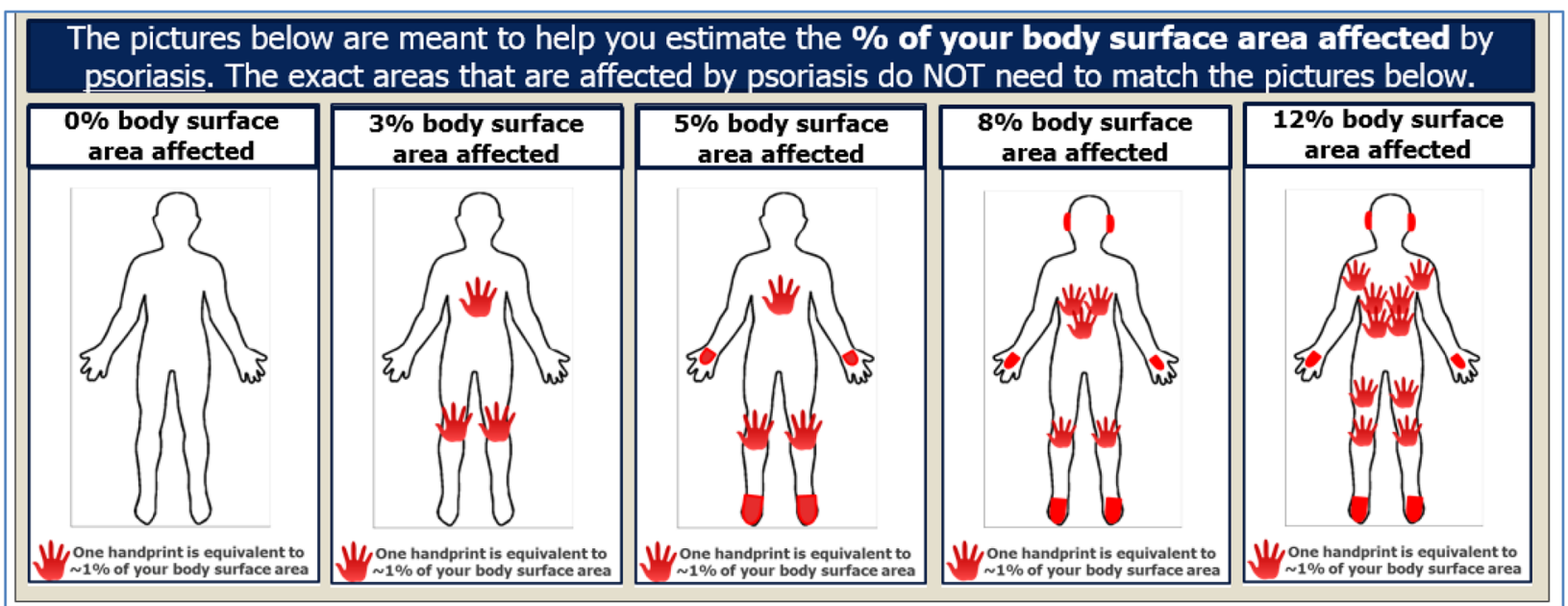

Fig. 1 Visual representation of body surface area affected by psoriasis (illustrative example of patient survey) 
(PASI) and percentage of body surface area (BSA) that remains affected 16 weeks after treatment initiation; probability that dermatology life quality index (DLQI) score will improve 16 weeks after treatment initiation; probability of loss of response within 1 year; probability of stopping therapy within 1 year for non-efficacy reasons; probability of an adverse event (AE; e.g., infection, headache, nausea); probability of a severe AE (e.g., serious infection, malignancy); and dosing (route of administration [ROA], setting, and frequency). Ranges for levels of potential outcomes were selected to span those that could be expected to be achieved by currently available biologic and new oral treatments. Probability of improvement in PASI and $\%$ of BSA remaining are correlated so this was included as one variable. To reduce the number of attributes tested, dosing- and frequency-related variables (dosing, route of administration, setting, and dosing frequency) were collapsed into one attribute. Pretests with physicians and patients validated understanding of attributes and levels tested in the DCE. Table 1 shows the set of attributes and ranges of levels of potential outcomes tested in the DCE for physicians and the corresponding language used for patients.

\section{Experimental Design}

Ideally, every combination of treatment attributes would be shown to respondents, but given our intention to align attribute combinations with those of marketed products and the sheer number of potential combinations, this was not feasible. Therefore, experimental design techniques were used to select the specific number of choice sets, the number of treatments presented in each choice set, and which attribute levels should be shown within each choice set. Specifically, choice model design autocall macros \%mktruns, \%mktex, and \%mkteval were used in SAS 9.4 (Cary, NC, USA) [21]. The \%mktruns macro suggests possible design sizes, the \%mktex macro creates a design with the maximum D-efficiency (to maximize the precision of the estimated parameters), and the \%mkteval macro is used to evaluate the design.
We restricted the experimental design from showing currently implausible combinations (e.g., for an oral product which met the highest levels of effectiveness based on PASI and BSA). In addition, we added a restriction that a product could not have both the highest levels of effectiveness for PASI and BSA measures as well as the lowest levels of probability for a serious adverse event (SAE). This restriction was intended to prevent the creation of a choice set for a treatment that would be chosen with little variation across respondents.

In this study, 16 choice sets, each containing three hypothetical treatments, were created. Each respondent saw a random set of eight choice sets to reduce respondent fatigue. Two treatment selections were made per choice set by each patient; the selection was based upon an assumption of treating either moderate or severe psoriasis. Figure 2 shows an illustrative choice set from which patient respondents had to choose.

\section{Study Recruitment}

Physician respondents were recruited via email invitation from an independent global panel company with a national panel of at least 6 million members from across the USA. The email invitation was not specific to the topic of interest to minimize self-selection or introduce bias into the survey.

Physician respondents were required to be able to read English and were screened to ensure they both specialize in and are board-certified/board-eligible in dermatology, have been in practice for 3-29 years, actively treat at least 25 unique psoriasis patients in a typical month, see at least eight moderate to severe psoriasis patients in a typical month, treat at least $20 \%$ of their moderate to severe psoriasis with biologics, and are not employed by a market research or advertising firm, or a pharmaceutical or medical equipment manufacturer.

Psoriasis patient respondents were recruited through two consumer/patient panels with a combined reach of at least 12.5 million 


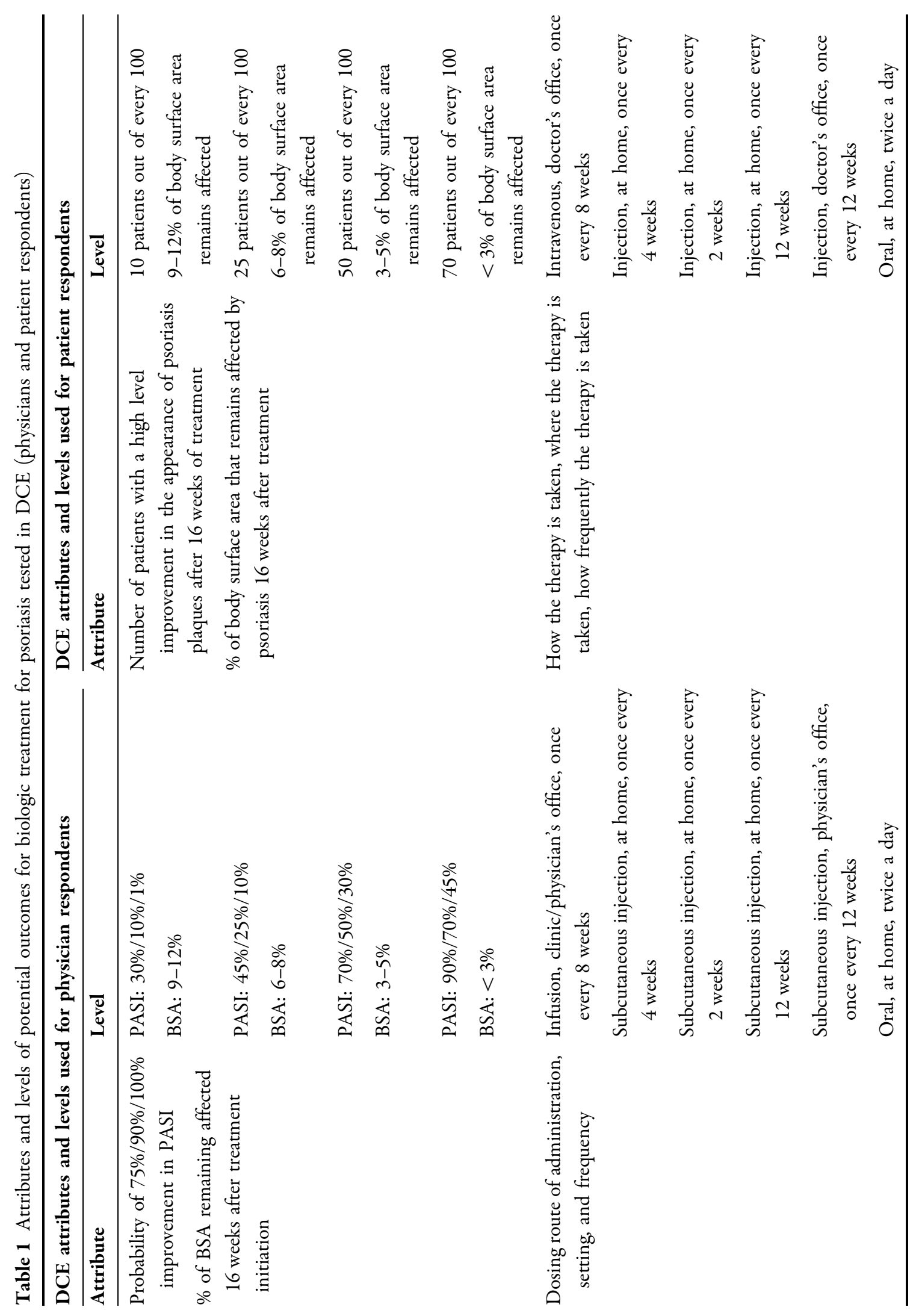




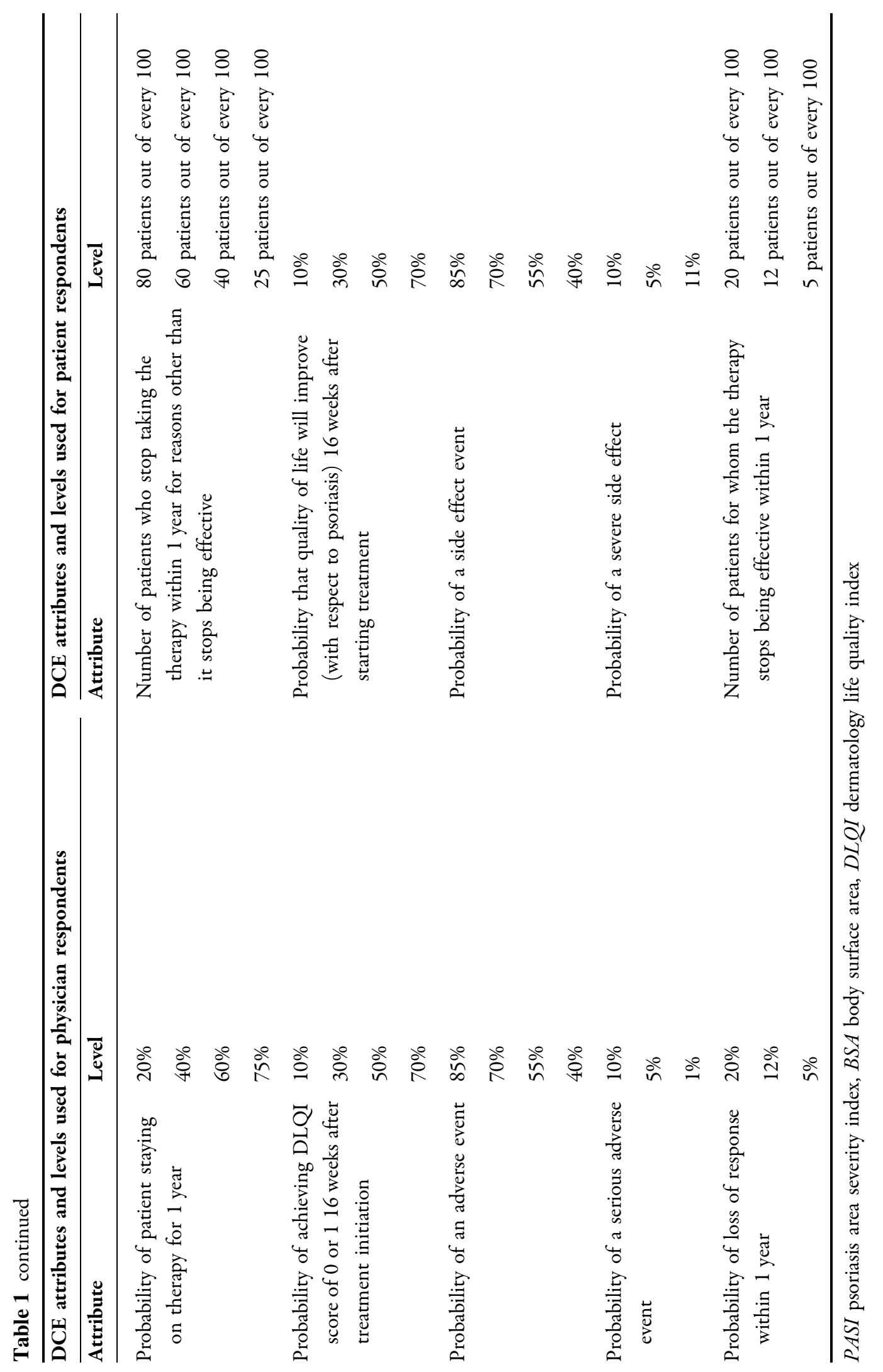




\begin{tabular}{|c|c|c|c|}
\hline & Product $\mathrm{X}$ & Product Y & Product $Z$ \\
\hline $\begin{array}{l}\text { Number of patients with a high level of } \\
\text { improvement in the appearance of psoriasis } \\
\text { plaques after } 16 \text { weeks of treatments }\end{array}$ & $\begin{array}{l}50 \text { patients out of every } \\
100\end{array}$ & $\begin{array}{l}10 \text { patients out of every } \\
100\end{array}$ & $\begin{array}{l}25 \text { patients out of every } \\
100\end{array}$ \\
\hline $\begin{array}{l}\% \text { of body surface area that remains affected } \underline{16} \\
\text { weeks after treatment }\end{array}$ & $\begin{array}{l}3-5 \% \text { of body surface area } \\
\text { remains affected }\end{array}$ & $\begin{array}{l}9-12 \% \text { of body surface } \\
\text { area remains affected }\end{array}$ & $\begin{array}{l}6-8 \% \text { of body surface area } \\
\text { remains affected }\end{array}$ \\
\hline $\begin{array}{l}\text { Probability that quality of life will improve (with } \\
\text { respect to psoriasis) } 16 \text { weeks after starting } \\
\text { treatment }\end{array}$ & $10 \%$ & $70 \%$ & $30 \%$ \\
\hline $\begin{array}{l}\text { Number of patients for whom the therapy stops } \\
\text { being effective within } 1 \text { year }\end{array}$ & $\begin{array}{l}20 \text { patients out of } \\
\text { every } 100\end{array}$ & $\begin{array}{l}5 \text { patients out of } \\
\text { every } 100\end{array}$ & $\begin{array}{l}12 \text { patients out of } \\
\text { every } 100\end{array}$ \\
\hline $\begin{array}{l}\text { Number of patients who stop taking the therapy } \\
\text { within one year for reasons other than it stops } \\
\text { being effective } \\
\text { Reasons could include side effects, convenience, } \\
\text { cost, etc. }\end{array}$ & $\begin{array}{l}80 \text { patients out of } \\
\text { every } 100\end{array}$ & $\begin{array}{l}25 \text { patients out of } \\
\text { every } 100\end{array}$ & $\begin{array}{l}40 \text { patients out of } \\
\text { every } 100\end{array}$ \\
\hline $\begin{array}{l}\text { Probability of a minor side effect } \\
\text { Side effects such as minor infection, headache, or } \\
\text { nausea }\end{array}$ & $70 \%$ & $40 \%$ & $55 \%$ \\
\hline $\begin{array}{l}\text { Probability of a severe side effect } \\
\text { Severe side effects include serious infections or } \\
\text { cancer }\end{array}$ & $1 \%$ & $10 \%$ & $1 \%$ \\
\hline $\begin{array}{l}\text { - How the therapy is taken } \\
\text { - Where the therapy is taken } \\
\text { - How frequency the therapy is taken }\end{array}$ & $\begin{array}{l}\text {-Injection } \\
\text { - Doctor's office } \\
\text { - Once every } 12 \text { weeks }\end{array}$ & $\begin{array}{l}\text { - Injection } \\
\text {-At home } \\
\text { - Once every } 12 \text { weeks }\end{array}$ & $\begin{array}{l}\text {-Injection } \\
\text {-At home } \\
\text { - Once every } 2 \text { weeks }\end{array}$ \\
\hline \multicolumn{4}{|l|}{$\begin{array}{l}\text { Which treatment would you select for } \\
\text { treatment of moderate psoriasis? }\end{array}$} \\
\hline
\end{tabular}

Fig. 2 Example of a choice set (DCE tested among patient respondents)

members. The panel companies are independent and have access to national panels of consumers/patients residing across the USA. Similar to physician recruitment, an email invitation was sent to the consumer/patient panel. The email invitation did not specify the topic of interest to minimize self-selection into the survey.

Psoriasis patient respondents were required to be able to read English and were screened to ensure they were adults (at least 18 years old), had moderate to severe psoriasis based on self-report of symptoms, and were not employed by a market research or advertising firm, or a pharmaceutical or medical equipment manufacturer.

\section{Data Cleaning Protocol}

Respondents were removed from the DCE if response patterns indicated lack of thoughtfulness, including short survey duration $(<10 \mathrm{~min})$ and straight-lining through several batteries of questions.

\section{Statistical Analyses}

Data from the DCE were analyzed with a multinomial logit model using PROC PHREG in SAS 9.4 (Cary, NC, USA). While the first choice is captured in the data, the second choice is unobserved in our design. Therefore, the unchosen treatment profiles are treated as censored values as in survival analyses. Effects coding was used to keep interpretation of results clear, consistent with previous DCE literature, and such that all levels of the attributes can be estimated [21].

The equation for the $j$ th choice task is as follows: 


$$
\begin{aligned}
u_{j}= & x_{11 j} \beta_{11 j}+x_{12 j} \beta_{12 j}+x_{13 j} \beta_{13 j}+x_{21 j} \beta_{21 j} \\
& +x_{22 j} \beta_{22 j}+x_{23 j} \beta_{23 j}+x_{24 j} \beta_{24 j}+x_{25 j} \beta_{25 j} \\
& +x_{31 j} \beta_{31 j}+x_{32 j} \beta_{32 j}+x_{33 j} \beta_{33 j}+x_{41 j} \beta_{41 j} \\
& +x_{42 j} \beta_{42 j}+x_{43 j} \beta_{43 j}+x_{51 j} \beta_{51 j}+x_{52 j} \beta_{52 j} \\
& +x_{53 j} \beta_{53 j}+x_{61 j} \beta_{61 j}+x_{62 j} \beta_{62 j}+x_{71 j} \beta_{71 j} \\
& +x_{72 j} \beta_{72 j}+e_{j}
\end{aligned}
$$

where $u$ is the perceived utility, $x_{i y j}$ is the $y$ th level of the $i$ th attribute in the $j$ th choice task, $\beta_{i y j}$ is the weight for the $y$ th level of the $i$ th attribute in the $j$ th choice task, and $e_{j}$ is the error component.

Note: Highest levels of each attribute were specified as the reference category.

Relative importance values, which reflect the strength of influence that tested attributes have on patient choice, were calculated as percentages that combined totaled 100\%. Relative importance was calculated as percentages based on the difference between the highest and lowest coefficient values for each attribute divided by the sum of the coefficient differences between the highest and lowest levels across all attributes, multiplied by 100 .

\section{RESULTS}

\section{Physician Recruiting and Clinical Characteristics}

The panel company sent email invitations to about 3400 unique members. Of these, 400 physicians clicked on the link to start the survey (response rate $=12 \%$ ). Of those, 203 qualified and completed the survey, but three respondents were removed through data cleaning procedures. Hence, the final physician sample size used in the analysis was 200 .

Table 2 summarizes descriptive statistics for the 200 dermatologists included in the final analysis. On average, sampled dermatologists had about 14 years in clinical practice and treated 114 unique psoriasis patients in a typical month, with $48 \%$ of these patients having moderate and $30 \%$ having severe psoriasis. Eighty-six percent of sampled dermatologists worked in a private office setting.
Table 2 Demographic and clinical characteristics of participating dermatologists

\begin{tabular}{lc}
\hline & $\begin{array}{c}\text { Sampled } \\
\text { dermatologists } \\
(\boldsymbol{n}=\mathbf{2 0 0})^{\mathrm{a}}\end{array}$ \\
\hline $\begin{array}{l}\text { Years in practice } \\
\text { Total number of psoriasis patients } \\
\text { treated in a typical month }\end{array}$ & $13.7(7.8)$ \\
Mild psoriasis patients seen in a typical & $35.3(36.1)$ \\
month & \\
Moderate psoriasis patients seen in a & $47.7(68.9)$ \\
typical month & \\
Severe psoriasis patients seen in a & $30.4(45.4)$ \\
typical month & \\
\% of moderate to severe psoriasis & $55.8(21.6)$ \\
patients on biologics & \\
Setting of primary practice & \\
Private office & $171(85.5 \%)$ \\
Community hospital & $4(2.0 \%)$ \\
Academic/teaching hospital & $25(12.5 \%)$ \\
Location of primary practice & \\
Urban & \\
Suburban & \\
Rural & $114(57.0 \%)$ \\
Male & \\
\hline a Values are count or mean (\% or standard deviation) \\
The range of this variable is impacted by screening cri- \\
teria for participation
\end{tabular}

\section{Patient Recruiting and Demographics}

The panel companies sent email invitations to about 50,000 unique panel members. Of these, 5500 respondents clicked on the link to start the survey (response rate $=11 \%$ ). Of those, 318 qualified and completed the survey and 122 were removed through data cleaning procedures. The final patient sample size used in the analysis was 196.

Table 3 summarizes the demographic and disease characteristics of sampled psoriasis 
Table 3 Demographic and clinical characteristics of participating psoriasis patients

\begin{tabular}{ll}
\hline Sampled psoriasis \\
patients $(n=196)^{\mathrm{a}}$
\end{tabular}

Severity of psoriasis symptoms at its worst

$\begin{array}{lr}\text { Moderate } & 89(45.4 \%) \\ \text { Severe } & 107(54.6 \%) \\ \text { Years since psoriasis diagnosis } & \\ <1 \text { year } & 10(5.1 \%) \\ 1-5 \text { years } & 81(41.3 \%) \\ 6-10 \text { years } & 44(22.4 \%) \\ 11-20 \text { years } & 30(15.3 \%) \\ 21+\text { years } & 31(15.8 \%)\end{array}$

Current treatment for psoriasis

$\begin{array}{ll}\text { Adalimumab } & 34(17.3 \%) \\ \text { Etanercept } & 32(16.3 \%) \\ \text { Infliximab } & 18(9.2 \%) \\ \text { Ustekinumab } & 16(8.2 \%) \\ \text { Apremilast } & 15(7.7 \%) \\ \text { Secukinumab } & 12(6.1 \%)\end{array}$

Doctor most frequently seen for psoriasis

$\begin{array}{lr}\text { Dermatologist } & 116(59.2 \%) \\ \text { Rheumatologist } & 32(16.3 \%) \\ \text { Other (i.e., PCP) } & 48(24.5 \%) \\ \text { Male } & 79(40.3 \%) \\ \text { Age } & 27(13.8 \%) \\ 18-29 \text { years old } & 82(41.8 \%) \\ 30-39 \text { years old } & 39(19.9 \%) \\ 40-49 \text { years old } & 43(21.9 \%) \\ 50-69 \text { years old } & 5(2.6 \%) \\ 70+\text { years old } & \\ \text { Ethnicity } & 155(79.1 \%) \\ \text { Non-Hispanic White } & 22(11.2 \%) \\ \text { Hispanic or Latino } & \end{array}$

Table 3 continued

\begin{tabular}{lc}
\hline & $\begin{array}{l}\text { Sampled psoriasis } \\
\text { patients }(\boldsymbol{n}=\mathbf{1 9 6})^{\mathbf{a}}\end{array}$ \\
\hline $\begin{array}{l}\text { Non-Hispanic Black or } \\
\text { African American }\end{array}$ & $12(6.1 \%)$ \\
Other (e.g., Asian/Pacific & $7(3.6 \%)$ \\
Islander, Native American) & \\
\hline Values are count (\%) & \\
PCP primary care physician &
\end{tabular}

patients. By design, the sample consisted of patients of most age, gender, and disease severity combinations. Of the sampled psoriasis patients, $45 \%$ reported having had moderate psoriasis and 55\% reported having had severe psoriasis when their disease was at its worst. Sixty percent of sampled psoriasis patients were female, $42 \%$ of patients were $30-39$ years of age, and $79 \%$ were non-Hispanic white. Patients reported that they were on the following treatments at the time they completed the survey: $17 \%$ adalimumab, $16 \%$ etanercept, $9 \%$ infliximab, 8\% ustekinumab, 8\% apremilast, and 6\% secukinumab.

\section{Stated Importance of Attributes: Physicians}

Physician-stated treatment attribute preferences for moderate and severe psoriasis were largely similar (maximum difference in mean ratings of 0.3 ) (Table 4). The distributions of mean ratings across moderate and severe psoriasis and across treatment attributes were largely on the middle to high end of the 9-point scale $(>6)$. Overall safety (mean score of 8.1) and low potential for AEs in real-world use (mean score of 8.0) were the highest rated attributes for both moderate and severe psoriasis, while reduction in BSA affected after 16 weeks of treatment was also rated highly (mean score of 8.0) for treating severe psoriasis patients. On average, physicians gave the lowest scores to the attributes of "ability to tailor dosing" and "mechanism of action" (mean scores $\leq 6.0$ ). 
Table 4 Physicians: stated importance of attributes

\begin{tabular}{|c|c|c|}
\hline & \multicolumn{2}{|c|}{$\begin{array}{l}\text { Stated importance of treatment attributes } \\
\text { Mean score (standard deviation) } \\
(1=\text { not at all critical; } 9=\text { extremely critical })\end{array}$} \\
\hline & Moderate psoriasis & Severe psoriasis \\
\hline \multicolumn{3}{|l|}{ Efficacy } \\
\hline Overall perception of efficacy & $7.8(1.4)$ & $7.9(1.5)$ \\
\hline Reduction in \% of BSA affected & $7.8(1.3)$ & $8.0(1.3)$ \\
\hline Maintenance of response over time & $7.7(1.4)$ & $7.8(1.4)$ \\
\hline Reduction in symptoms associated with lesions & $7.6(1.5)$ & $7.7(1.4)$ \\
\hline Reduction in redness, thickness, and scale & $7.4(1.5)$ & $7.5(1.5)$ \\
\hline Improvements in patients' $\mathrm{QoL}$ & $7.3(1.9)$ & $7.4(1.8)$ \\
\hline Rapidity of response after initiating treatment & $6.4(1.6)$ & $6.7(1.6)$ \\
\hline Improvement based on key metrics in real-world data & $6.4(2.0)$ & $6.4(2.1)$ \\
\hline Improvement based on key metrics in trial data & $6.0(2.1)$ & $6.1(2.2)$ \\
\hline \multicolumn{3}{|l|}{ Safety } \\
\hline Overall perception of safety & $8.1(1.2)$ & $8.1(1.2)$ \\
\hline Low potential for AEs based on real-world data & $8.0(1.3)$ & $8.0(1.3)$ \\
\hline Low potential for AEs based on clinical trial data & $7.9(1.4)$ & $7.9(1.4)$ \\
\hline Patient-specific contraindications & $7.4(1.6)$ & $7.4(1.6)$ \\
\hline Low potential for tolerability issues & $7.0(1.5)$ & $6.9(1.5)$ \\
\hline \multicolumn{3}{|l|}{ Other } \\
\hline $\begin{array}{l}\text { Overall perception of performance based on } \\
\text { non-efficacy or safety metrics }\end{array}$ & $6.9(1.7)$ & $7.0(1.6)$ \\
\hline Affordable/reasonable patient out-of-pocket cost & $7.8(1.4)$ & $7.8(1.4)$ \\
\hline Minimal access and coverage issues & $7.6(1.6)$ & $7.6(1.6)$ \\
\hline Familiarity/experience with the therapy & $7.2(1.5)$ & $7.3(1.6)$ \\
\hline Maintenance dosing frequency & $6.4(1.5)$ & $6.4(1.6)$ \\
\hline $\mathrm{ROA}$ & $6.2(1.8)$ & $6.1(1.8)$ \\
\hline Ability to tailor dosing & $5.9(1.8)$ & $6.0(1.8)$ \\
\hline Mechanism of action & $5.6(1.8)$ & $5.6(1.9)$ \\
\hline
\end{tabular}

\section{Stated Importance of Attributes: Patients}

Patients' stated preferences were concordant for moderate and severe disease (maximum difference: 0.2) (Table 5). Mean ratings of safety and efficacy metrics ranged from 6.9 to 8.2. Among other metrics, out-of-pocket cost was rated highly (8.0), while ratings for dosing frequency and $\mathrm{ROA}$ ranged from 6.6 to 7.0. Attributes were 
Table 5 Psoriasis patients; stated importance of attributes

\begin{tabular}{|c|c|c|}
\hline & \multicolumn{2}{|c|}{$\begin{array}{l}\text { Stated importance of treatment attributes } \\
\text { Mean score (standard deviation) } \\
(1=\text { not at all critical; } 9=\text { extremely critical })\end{array}$} \\
\hline & Moderate psoriasis & Severe psoriasis \\
\hline \multicolumn{3}{|l|}{ Efficacy } \\
\hline Reduction in symptoms associated with lesions & $8.2(1.4)$ & $8.1(1.3)$ \\
\hline Reduction in redness, thickness, and scale & $8.0(1.4)$ & $8.1(1.2)$ \\
\hline Maintenance of response over time & $8.0(1.3)$ & $8.1(1.3)$ \\
\hline Improvement in QoL & $8.0(1.3)$ & $7.9(1.6)$ \\
\hline$\%$ reduction in BSA affected & $7.8(1.4)$ & $8.0(1.4)$ \\
\hline Rapidity of response after initiating treatment & $7.7(1.4)$ & $7.8(1.4)$ \\
\hline $\begin{array}{l}\text { Scientific or clinical information presented by a doctor } \\
\text { that demonstrates efficacy }\end{array}$ & $7.2(1.8)$ & $7.3(1.8)$ \\
\hline $\begin{array}{l}\text { Scientific or clinical information about efficacy from } \\
\text { sources other than a doctor }\end{array}$ & $6.9(1.7)$ & $7.0(2.0)$ \\
\hline \multicolumn{3}{|l|}{ Safety } \\
\hline Low potential for serious adverse events & $8.1(1.5)$ & $8.1(1.2)$ \\
\hline Low potential for minor side effects & $7.6(1.8)$ & $7.6(1.5)$ \\
\hline \multicolumn{3}{|l|}{ Other } \\
\hline Therapy is affordable/has reasonable out-of-pocket costs & $8.0(1.4)$ & $8.0(1.4)$ \\
\hline How often you need to receive a medication & $6.9(2.1)$ & $7.0(2.0)$ \\
\hline $\begin{array}{l}\text { How the medication is taken (e.g., orally as a pill or tablet, } \\
\text { subcutaneous injection, infusion) }\end{array}$ & $6.6(2.5)$ & $6.8(2.4)$ \\
\hline
\end{tabular}

consistently rated as intermediate to high importance $(>6)$ on the 9-point scale.

\section{Differences in Stated Importance of Attributes: Physicians vs. Patients}

Physicians seemingly placed higher value in objective clinical measures (e.g., reduction in \% of BSA affected), whereas patients placed higher value in subjective measures that would most directly impact them (QoL, signs, symptoms).

Patients rated reduction in signs (redness, thickness, scale) and symptoms higher than BSA, although patients and physicians had the same numeric ratings for BSA reduction.
Patients rated QoL improvement and maintenance of response higher than physicians. Differences between physicians and patients are clinically meaningful though not necessarily statistically significant. However, patient-stated preference for QoL relative to physician-stated preference was statistically significant.

\section{Results from Derived DCE: Relative Importance and Importance Weights for Moderate Psoriasis Patients (Physician Model)}

In the physician model for moderate psoriasis (Fig. 3), dosing was the most important 
Relative Importance of Attributes (Out of 100\%)

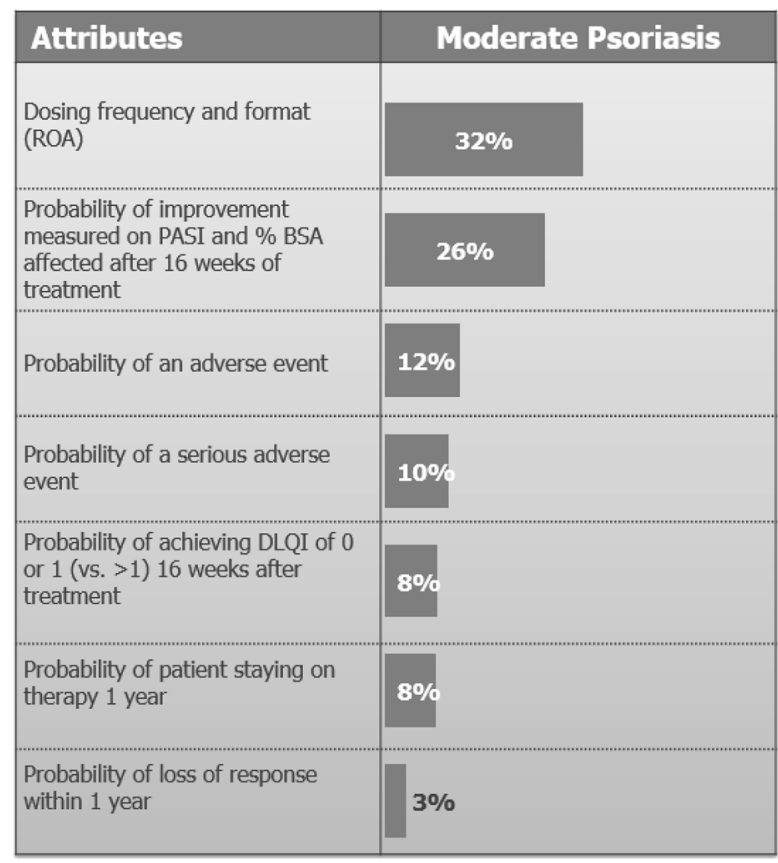

Fig. 3 Relative importance of attributes (moderate psoriasis-physician model)

attribute in driving treatment choice (RI 32\%), followed by probability of improvement measured by PASI and BSA affected after 16 weeks of treatment (RI 26\%). Safety attributes were next highest [probability of an adverse event (RI $12 \%)$, probability of a serious adverse event (RI $10 \%)$, but considerably lower than dosing and efficacy. The probability of loss of response within 1 year (RI 3\%) was considered the least important treatment attribute compared to the others, and was the only attribute where the level preference weights were not naturally ordered.

Figure 4 shows the estimated importance weights for considerations when treating moderate psoriasis patients in the physician model and $95 \%$ confidence intervals (CIs) for the seven different treatment attributes tested in the DCE.

Physicians viewed most levels of improvement in PASI and BSA as significantly different when considering them for treatment of moderate psoriasis. For the probability of PASI 75/90/100 and BSA remaining affected attribute, the most valued improvement was from the moderate level (level 2) to the high level (level 3). There was no statistically significant difference in physicians' impression of the product for moderate psoriasis if it improved from the high level (level 3) to the very high level (level 4). For the dosing attribute, physicians viewed an IV ROA as the least appealing compared to subQ injection in any setting or at any tested frequency. Physicians also viewed oral dosing as a statistically significantly preferred ROA option compared to subQ or IV administration for treatment of moderate psoriasis. The model shows that physicians considered a difference in the risk of an $\mathrm{AE}$ of $70 \%$ vs. $55 \%$ as significant, and differences between all levels of probability of an SAE (10\% vs. 5\%, $5 \%$ vs $1 \%$ ) as significant as well.

\section{Results from Derived DCE: Relative Importance and Importance Weights for Severe Psoriasis Patients (Physician Model)}

In the physician model for treatment of severe psoriasis (Fig. 5), the probability of improvement measured by PASI and BSA affected after 16 weeks of treatment (RI 42\%) was the most important attribute in driving treatment choice. Dosing frequency and format (RI 22\%) ranked as the second most important attribute and probability of loss of response within 1 year (RI $1 \%$ ) as the least important across all attributes tested. Additionally, physicians placed a low level of importance on safety attributes (RI of probability of an adverse event and probability of a serious adverse event were both $8 \%$ ).

Figure 6 shows the estimated importance weights for considerations when treating severe psoriasis patients in the physician model and 95\% confidence intervals (CIs) for the seven different treatment attributes tested in the DCE

For probability of PASI 75/90/100 and percentage of BSA remaining affected, the greatest difference was observed from the moderate level (level 2) to the high level (level 3). There was also a significant difference between the high level (level 3) to the very high level (level 4), reflecting the overall importance of efficacy in the severe population. Within the ROA/ 


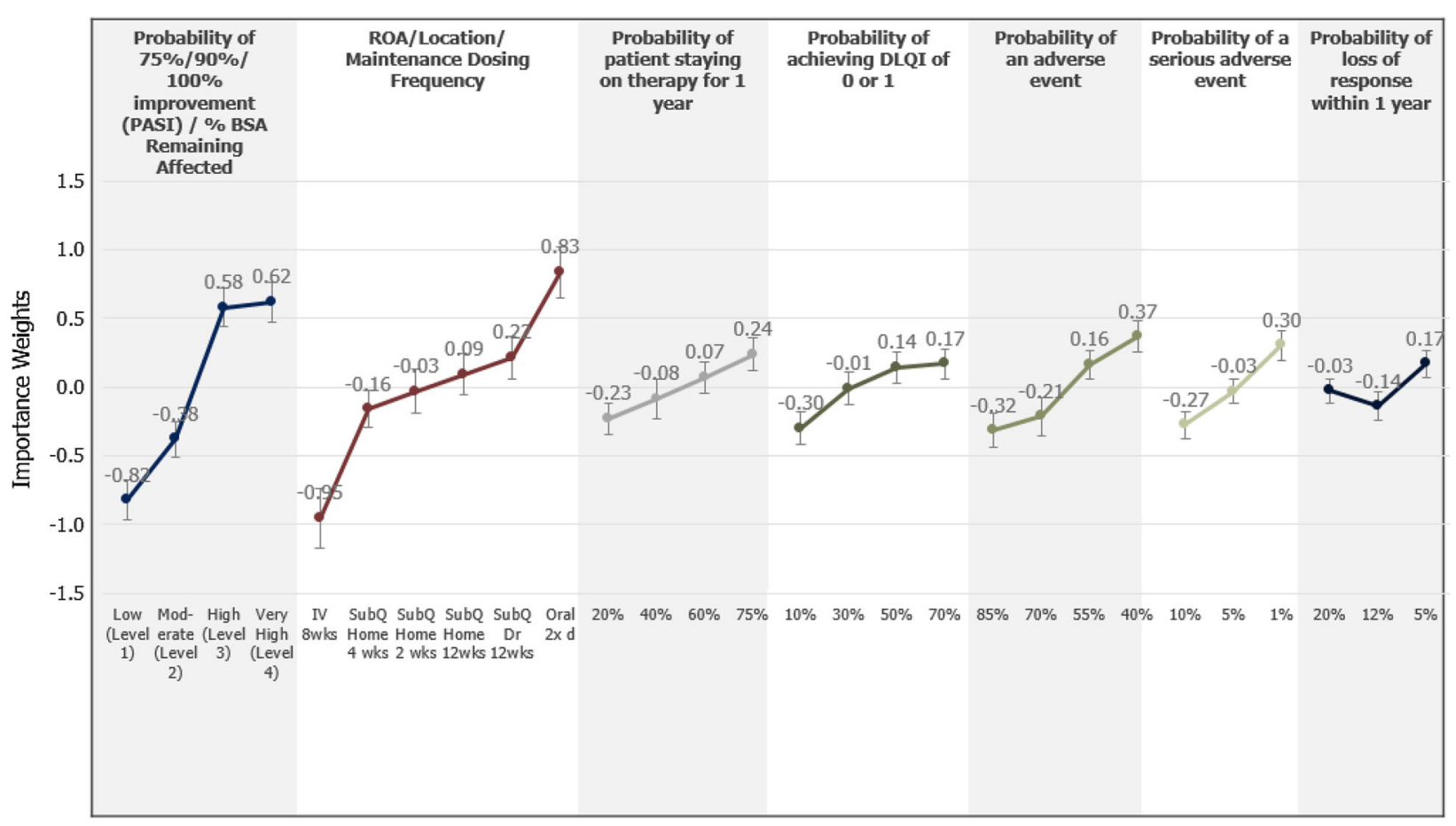

Fig. 4 Importance weights for attribute levels (moderate psoriasis-physician model). Non-overlapping error bars indicate statistically significant differences across levels within attributes at the $95 \%$ confidence level. The vertical distance between the first and last levels within an attribute indicates the relative importance of the attribute compared to other attributes (i.e., the longer the line, the more important the attribute). A larger distance between two points would imply higher sensitivity between two levels of the same attribute, or two levels of another attribute in the

location/maintenance dosing frequency attribute, IV dosing was significantly less favorable versus other ROAs; there were no significant differences between the various subQ dosing frequencies. For the "probability of patient staying on therapy for 1 year" attribute, the only statistically significant difference was for increasing probability from $60 \%$ to $75 \%$. An increase in probability of achieving DLQI of 0 or 1 from $10 \%$ to $50 \%$ was also significant, as was a decrease in the probability of an adverse event from $85 \%$ to $55 \%$. There were no statistically significant differences between levels for probability of a serious $\mathrm{AE}$ and probability of loss of response within 1 year. same model. Interpretation of coefficients: while each coefficient/importance weight in isolation is meaningless, when looked at in comparison to other importance weights it offers an estimate of the relative importance of one attribute level over another. For example, among physicians, an oral product that is administered at home, twice a day, is considered about 4 times more important than a subcutaneous injection that is administered at home, once every 12 weeks $(0.83 / 0.22=3.77)$. Such comparisons can also be made across attributes

\section{Results from Derived DCE: Relative Importance and Importance Weights for Moderate Psoriasis Patients (Patient Model)}

In the patient model for moderate psoriasis (Fig. 7), dosing (RI 29\%) was the most important attribute in driving treatment choice followed closely by the number of patients with high level of improvement in psoriasis plaques and $\%$ BSA affected after 16 weeks of treatment $(27 \%)$. The remaining attributes, including safety, were relatively less important compared to ROA/location/maintenance dosing frequency and probability of improvement. The number of patients for whom therapy stops being 


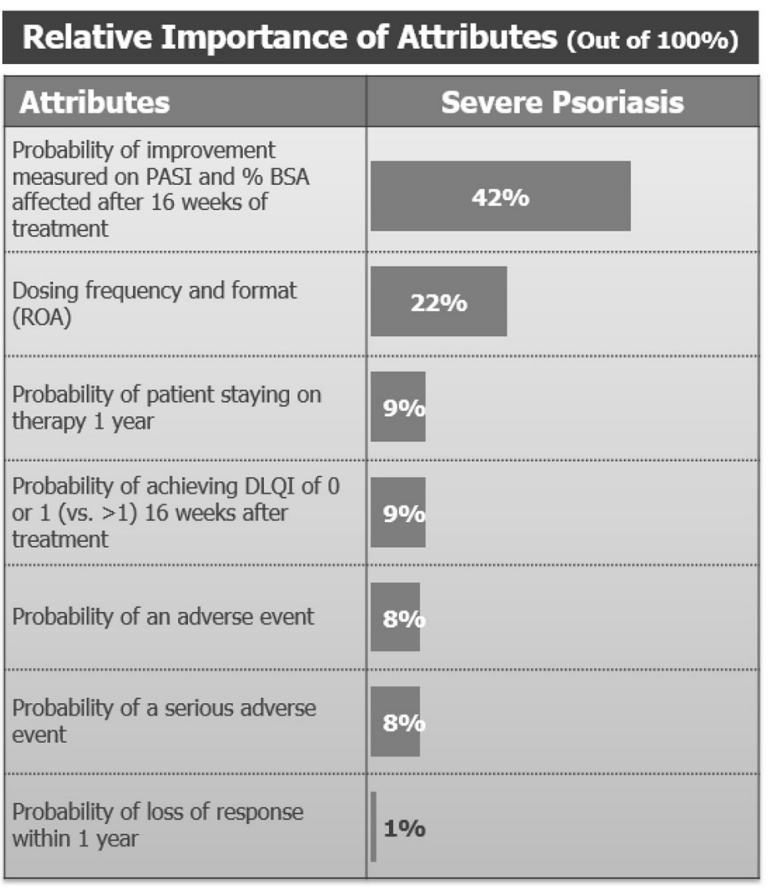

Fig. 5 Relative importance of attributes (severe psoriasisphysician model)

effective within 1 year (RI $0 \%$ ) was the least important treatment attribute compared to all others.

Figure 8 shows the estimated importance weights for considerations when thinking of moderate disease in the patient model and 95\% confidence intervals (CIs) for the seven different treatment attributes tested in the DCE.

In the patient model for treatment of moderate psoriasis, oral administration was statistically significantly preferred compared to any of the subQ dosing options, and IV administration was the least preferred among all choices. The difference between the moderate level (level 2) and the high level (level 3) of effectiveness was significant and showed the greatest magnitude of difference between levels for moderate psoriasis. There was no statistically significant difference between the high level (level 3) and the very high level (level 4 ). The model shows that patients considered a difference in the risk of an adverse effect from $70 \%$ to $55 \%$ and the difference of a risk of a severe adverse effect from 5\% to $1 \%$ as significant.

\section{Results from Derived DCE: Relative Importance and Importance Weights for Severe Psoriasis Patients (Patient Model)}

In the patient model for treatment of severe psoriasis (Fig. 9), the proportion of patients with a high level of improvement in psoriasis plaques and BSA remaining affected (RI 36\%) was the predominant driver of treatment choice. The other six attributes were much less important relative to this key efficacy attribute, with the "probability that quality of life will improve (with respect to psoriasis)" after 16 weeks of treatment (RI 16\%) as the second most important. The number of patients for whom therapy stops being effective (RI 4\%) was the least important across all attributes tested. Safety (probability of a minor adverse effect and of a severe adverse effect) was considered relatively less important in the patient model for severe psoriasis.

Figure 10 shows the estimated importance weights for considerations when thinking of severe disease in the patient model and 95\% confidence intervals (CIs) for the seven different treatment attributes tested in the DCE.

The most meaningful differences for the proportion of patients with improvement were between the moderate level (level 2) and the high level (level 3) as well as between the high level (level 3) and the very high level (level 4). IV administration was significantly less preferred relative to other dosing options, with the exception of every 4 week subQ dosing, which ranked nearly as low as IV administration. No difference in preference was observed between oral and other subQ dosing options. Relatively less importance was placed on safety concerns for treatment of severe disease, with only a difference of $85 \%$ vs $70 \%$ for probability of a minor adverse effect reaching significance. Only a difference of $10 \%$ vs. $1 \%$ was significant for the probability of a severe adverse effect. 


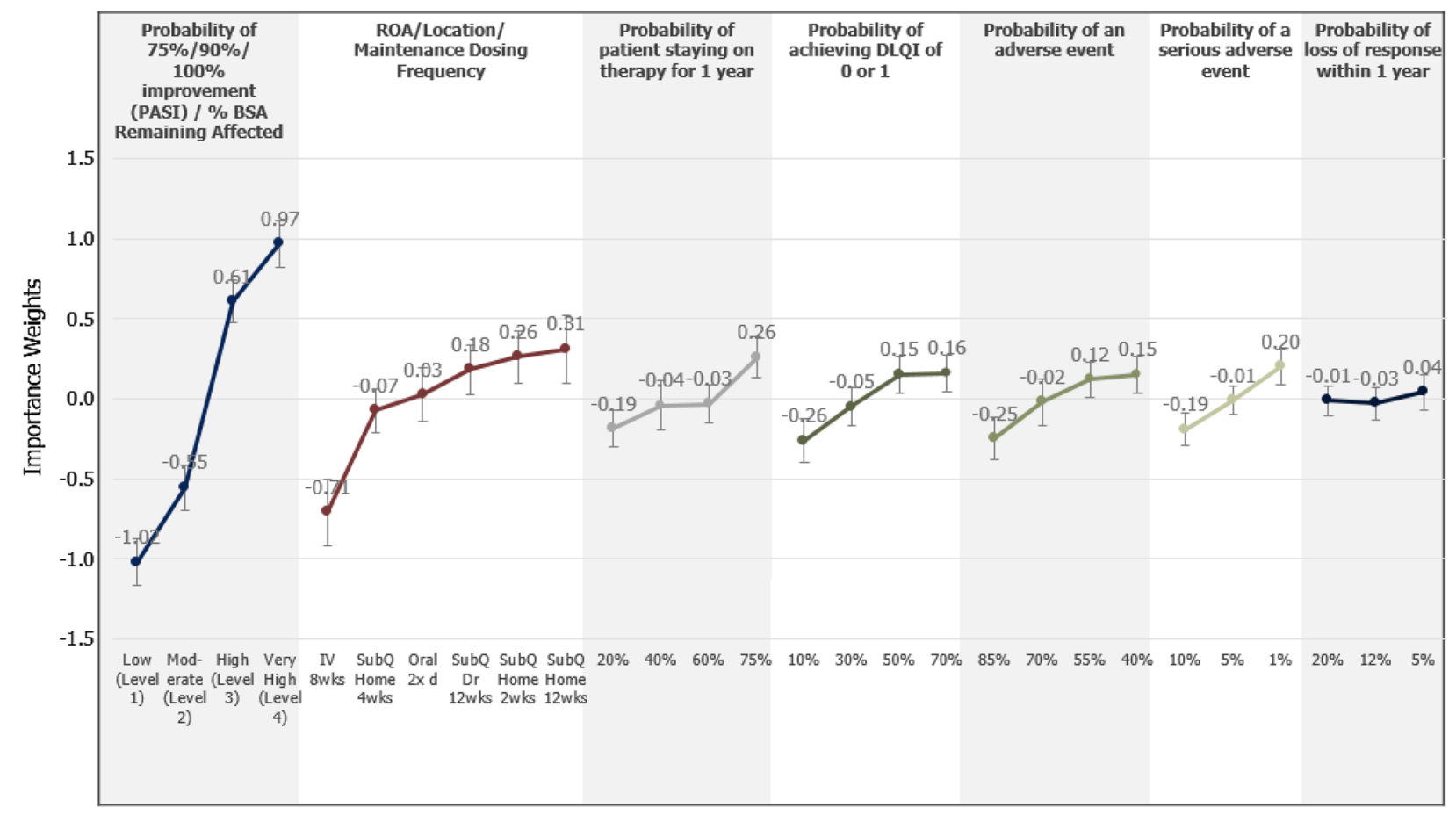

Fig. 6 Importance weights for attribute levels (severe psoriasis patients-physician model). Non-overlapping error bars indicate statistical significant differences across levels within attributes at the $95 \%$ confidence level. The vertical distance between the first and last levels within an attribute indicates the relative importance of the attribute

\section{DISCUSSION}

\section{Comparisons of Physician-Derived Attribute Preferences Based on Disease Severity: Moderate vs. Severe Psoriasis}

Physician preferences for treatment of moderate and severe psoriasis were broadly consistent. For moderate disease, physicians most heavily valued dosing frequency and efficacy (improvement in PASI score and BSA), almost equally. Similarly, physicians found efficacy and dosing frequency to be most important for choice of treatment for severe psoriasis; however, efficacy was nearly twice as important as dosing frequency for severe disease (as compared to treatment of moderate disease). For both moderate and severe psoriasis, safety, probability of loss of response within 1 year, and probability of patients staying on therapy for 1 year were compared to other attributes (i.e., the longer the line, the more important the attribute). A larger distance between two points would imply that a higher sensitivity exists between two levels of the same attribute, or two levels of another attribute in the same model

less important, suggesting that physicians were willing to trade lack of treatment durability and safety for short-term efficacy and convenience of dosing regimen.

\section{Comparisons of Patient-Derived Attribute Preferences Based on Disease Severity: Moderate vs. Severe Psoriasis}

Interestingly, the trends for attribute preference were relatively consistent among patients regardless of disease severity. Patients valued efficacy and dosing frequency as the top treatment attributes. For moderate disease, dosing frequency and efficacy were almost equally important to patients. For severe disease, efficacy was more than twice as important as dosing frequency and probability of improvement in DLQI. Achieving a very high level of clinical response was important for severe psoriasis 
Relative Importance of Attributes (Out of $100 \%$ )

\begin{tabular}{|c|c|}
\hline Attributes & Moderate Psoriasis \\
\hline $\begin{array}{l}\text { - How therapy is taken } \\
\text { - Where therapy is taken } \\
\text { - How frequent therapy is taken }\end{array}$ & $29 \%$ \\
\hline $\begin{array}{l}\text { Number of patients with a high level } \\
\text { of improvement in the appearance of } \\
\text { psoriasis plaques after } 16 \text { weeks of } \\
\text { treatments and \% of body surface } \\
\text { area that remains affected }\end{array}$ & $27 \%$ \\
\hline Probability of a minor adverse event & $16 \%$ \\
\hline $\begin{array}{l}\text { Probability that quality of life will } \\
\text { improve (with respect to psoriasis) }\end{array}$ & $13 \%$ \\
\hline Probability of a severe adverse event & $10 \%$ \\
\hline $\begin{array}{l}\text { Number of patients who stop taking } \\
\text { the therapy within one year for } \\
\text { reasons other than it stops being } \\
\text { effective }\end{array}$ & $5 \%$ \\
\hline $\begin{array}{l}\text { Number of patients for whom the } \\
\text { therapy stops being effective within } \\
1 \text { year }\end{array}$ & $0 \%$ \\
\hline
\end{tabular}

Fig. 7 Relative importance for attributes (moderate psoriasis-patient model)

patients, as a statistically significant difference was observed between achieving a very high level (level 4) vs a high level (level 3) of response. In contrast, similar findings were not seen in the moderate patient model. Of note, patients valued durability of treatment and safety to a much lesser extent compared to efficacy and dosing frequency attributes. Relative to the moderate patient model, there was less sensitivity to varying safety levels in the severe patient model.

\section{Comparisons of Physician- and Patient-Derived Attribute Preferences}

The parallel DCE design for both physicians and patients facilitates comparisons of attribute preferences between these stakeholders. However, direct comparisons should be limited given that the data were modeled separately. Nonetheless, our findings suggest similarities in preferences for treatment attributes between physicians and patients. With consideration of treatment for both moderate and severe psoriasis the most and least important treatment attributes were identical between physicians and patients. The most important attribute for moderate psoriasis was dosing, while the most important attribute for severe psoriasis was related to efficacy. This indicates that the primary desired outcome for moderate disease was different for that of severe disease; specifically, in severe disease, the probability of improvement was paramount while in moderate disease attributes related to dosing frequency and route of administration were slightly more important than efficacy. Conversely, the least important attribute for both physicians and patients was the probability of loss of response within 1 year, regardless of severity of disease. This finding suggests that both physicians and patients were more focused on short-term outcomes and were less concerned with long-term responses despite psoriasis being a chronic disease. Further studies are needed to address the reasons underlying this observation. Furthermore, amelioration of psoriasis symptoms correlated with a greater improvement in QoL.

This study indicated that disease severity was a significant driver of therapy choice for both physicians and patients. When considering treatment for moderate psoriasis, physicians and patients most heavily weighted dosing parameters. Twice-daily oral dosing was preferred by both stakeholders over IV and subQ routes of administration, regardless of frequency or location of administration. In contrast, for severe psoriasis, efficacy attributes were most critical; physicians and patients preferred treatments with a higher probability of substantial improvement. Intuitively, respondents believed that greater efficacy is expected with greater severity of disease. Interestingly, greater emphasis was placed on short-term response, as the potential for stopping therapy through 1 year or loss of effectiveness ranked low as concerns. Further studies are warranted to more fully understand why drivers of maintenance of response (e.g., willingness to recognize psoriasis as a chronic disease, increasingly greater number of treatment options if one fails, etc.) are valued to a lesser extent over more short-term efficacy. 


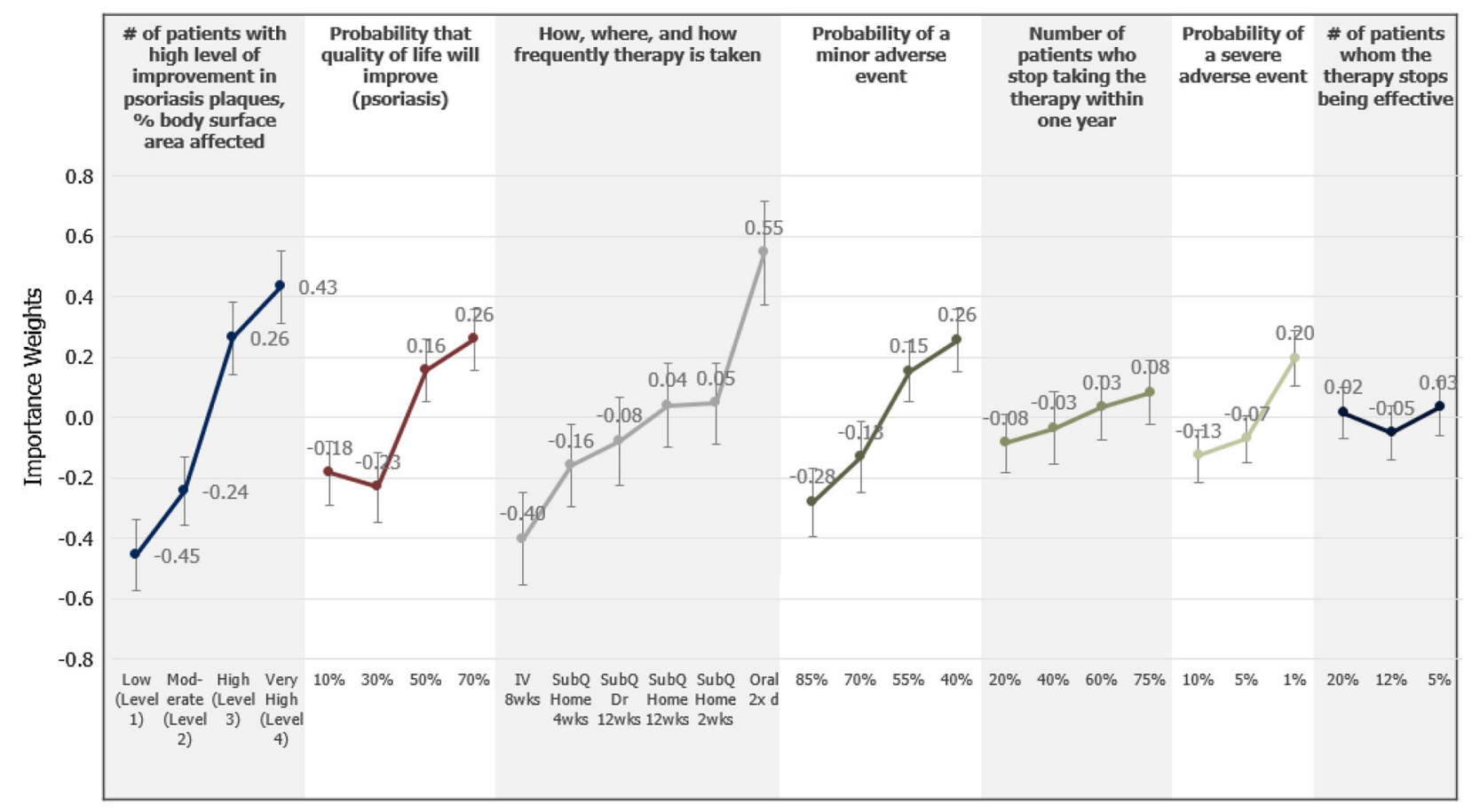

Fig. 8 Importance weights for attribute levels (moderate psoriasis- patient model). Non-overlapping error bars indicate statistical significant differences across levels within attributes at the $95 \%$ confidence level. The vertical distance between the first and last levels within an attribute indicates the relative importance of the attribute compared

\section{Differences Between Stated Importance and Importance from DCE}

While the surveys included both stated and derived importance exercises for treatment attributes, relative importance (RI) values derived from the DCE are significantly more reliable in real-world decision-making given the trade-offs that have to be made between attributes. Stated importance levels are useful to establish a baseline understanding, but differences between stated and derived importance are expected, given that the latter requires one to prioritize attributes.

Not surprisingly, discrepancies between stated importance (mean scores on a 1 [not at all critical] to 9 [extremely critical] scale of importance) and modeled importance (i.e., derived from the DCE) of treatment attributes were identified. When tasked with rating the importance of various efficacy, safety, and other to other attributes (i.e., the longer the line, the more important the attribute). A larger distance between two points would imply that a higher sensitivity exists between two levels of the same attribute, or two levels of another attribute in the same model

factors in treatment choice, physicians and patients tended to rate each attribute relatively highly ( $\geq 6$ on the 9 -point scale). This may be explained, in part, by there being no risk for stating that all attributes are relatively important and that trade-offs between attributes were not required. However, in the DCE, trade-offs between attributes had to be made to determine their relative importance. Given the nature of the two separate exercises, discrepancies between stated importance and modeled importance were inevitable.

There was a higher degree of alignment between stated and derived importance from the DCE for severe psoriasis. The stated importance of efficacy measures for moderate psoriasis was high for physicians and patients alike, whereas results from the DCE suggested that ROA is more important than efficacy. Conversely, the stated importance of treatment attributes for severe psoriasis aligned with 


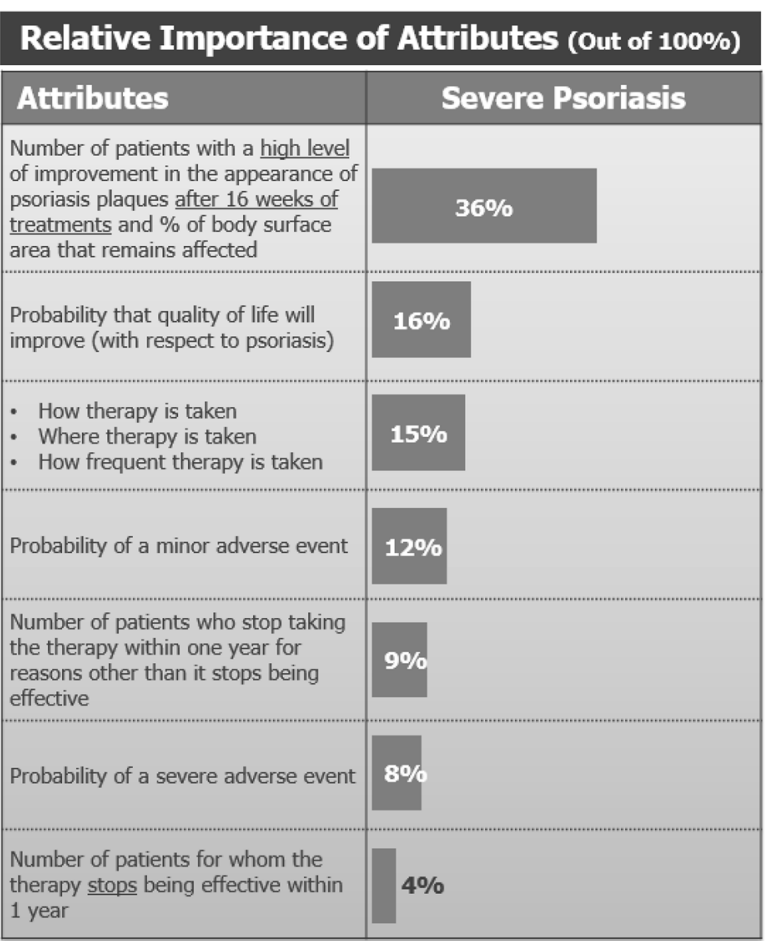

Fig. 9 Relative importance for attributes (severe psoriasis-patient model)

results for modeled (or relative) importance from the DCE. The stated importance of various efficacy measures was rated highly and were consistent with probability of improvement (PASI and BSA) from the DCE.

\section{Strengths of the Research and Comparisons from the Literature}

Prior DCE studies for psoriasis have provided insight into individual stakeholder preferences for psoriasis treatments and acceptable trade-offs between risks and benefits. Schaarschmidt et al. [18] found that psoriasis patients considered treatment location (e.g., at home, outpatient clinic) and method of delivery (e.g., oral, injection) as the most important attributes for selecting psoriasis treatments. The relative importance of process-related attributes (i.e., treatment location, method of delivery, frequency, cost) were higher than for adverse effect-related attributes. Probability of benefit was second most important. Seston et al. [19] observed that psoriasis patients found the greatest benefit in low risks of skin cancer and liver damage, and preferred treatments that achieve moderate improvement more quickly. Process attributes were of moderate importance.

Similar to Schaarschmidt et al. [18], our study found that dosing frequency and efficacy are the most important attributes for psoriasis patients. As compared to other aforementioned DCE studies, adverse events were of secondary importance in psoriasis treatment choice.

However, to our knowledge, our study was unique in that it provides perspective on preferences for treatment attributes for both physicians and patients using a parallel DCE design. Additionally, our study characterizes preferences for treatment attributes on the basis of psoriasis severity (moderate versus severe). A further strength of this research was the incorporation of attributes and attribute levels relevant to newer agents used for treating psoriasis in clinical practice.

\section{Limitations with Study and Discrete Choice Methodology}

While the study design using DCE methodology had several strengths, several limitations should be noted. First, the analysis was limited to data provided only by respondents, which may limit the ability to generalize findings to broader groups of physicians and patients. Physicians participating in the DCE were asked to make choices for favorability of attributes of treatments for moderate and severe psoriasis at an aggregate level rather than at an individual patient level. As such, some considerations (e.g., specific patient preferences, prior treatment history/response, and comorbidities) were not taken into account when making treatment choices. Additionally, respondents had to make some assumptions for their choices based on hypothetical circumstances (e.g., answering for severe disease if they were classified as having moderate disease). Lastly, implausible choice sets (e.g., administered orally and had the highest level of effectiveness) were not tested in the DCE given attributes of currently available marketed treatments. 


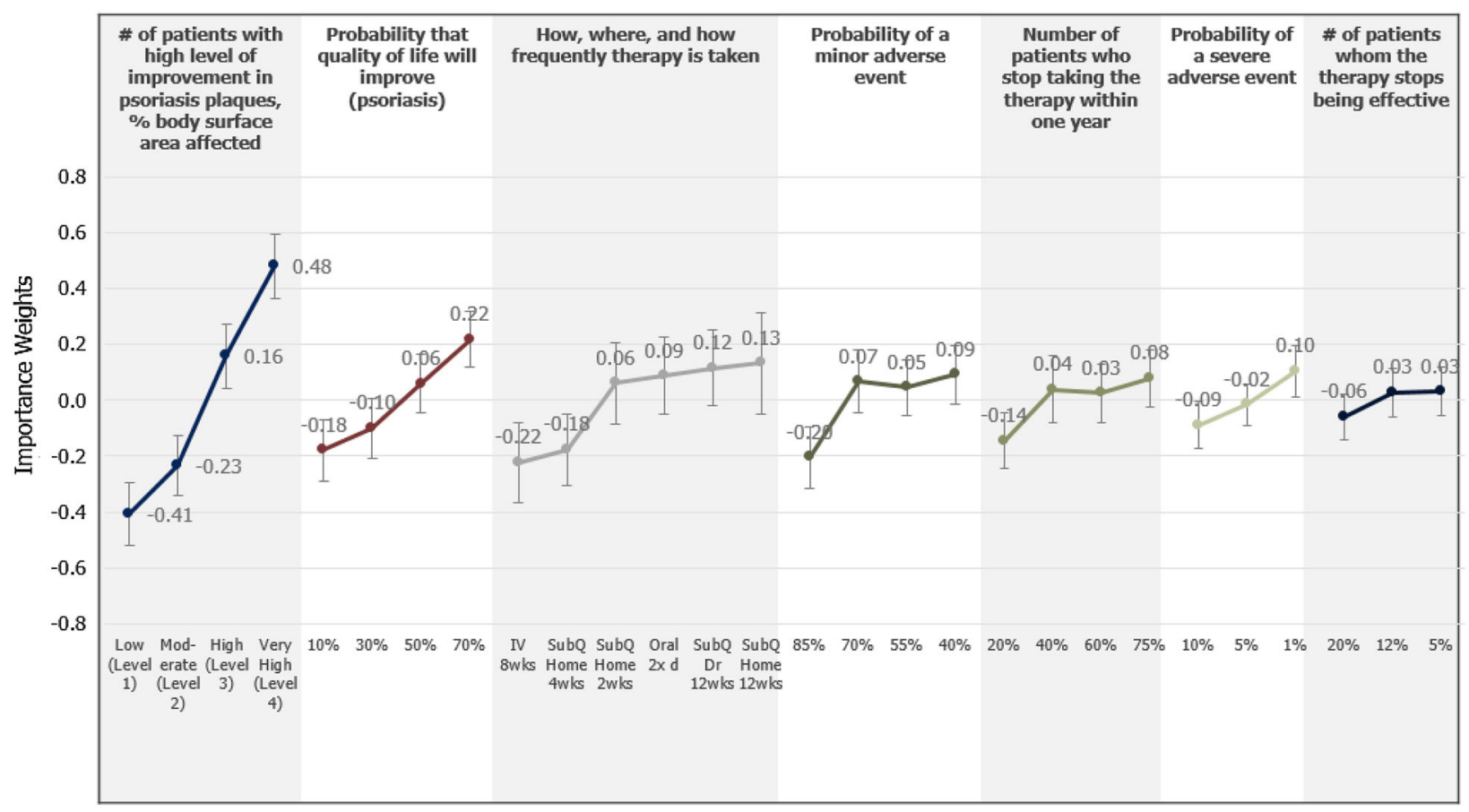

Fig. 10 Importance weights for attribute levels (severe psoriasis patients-patient model). Non-overlapping error bars indicate statistical significant differences across levels within attributes at the $95 \%$ confidence level. The vertical distance between the first and last levels within an attribute indicates the relative importance of the attribute compared

To ensure that the DCE had a design that respondents could feasibly complete without significant fatigue/burden, the numbers of attributes and levels tested were constrained. To achieve a feasible experimental design and reduce correlation between variables, efficacy (probability of improvement in PASI and \% of BSA remaining affected) and dosing-related attributes (route of administration, setting, and dosing frequency) were two attributes that had multiple components. Results may have varied if the elements were tested separately given a different experimental design. Various other attributes could have been included in the design, but were excluded to ensure the task was manageable for respondents. Such potential attributes included, but are not limited to, physician recommendation (patient design only), usage of treatment by family members (patient design only), degree of patient engagement in self-care (physician and patient to other attributes (i.e., the longer the line, the more important the attribute). A larger distance between two points would imply that a higher sensitivity exists between two levels of the same attribute, or two levels of another attribute in the same model

design). Additionally, the treatment attributes tested in the DCE were clinically focused so that the impact of cost and patient affordability were not included in decision-making. Future work should consider including non-clinical and other aforementioned attributes to understand their impact on treatment preference.

Finally, response rates for both physician and patient surveys were relatively low given a large number of respondents not clicking on the survey invite link, which could be due to a number of reasons (e.g., lack of interest, etc.).

\section{Shared Decision-Making Between Physicians and Patients}

Prior research indicated that shared decision-making between physicians and patients led to greater levels of satisfaction with treatment and ultimately better health outcomes, 
particularly for chronic conditions such as psoriasis [14-17, 22]. Knowing that physicians and patients may have similar preferences for attributes of treatment could enable patients to more readily voice their opinion and be an active participant in treatment decision-making. From the physician's perspective, understanding similarities in treatment preferences may encourage greater proactive engagement of patients in making shared decisions [17]. Taken together, findings from this study could help promote more transparent and meaningful discussions on the advantages and disadvantages of therapeutic choices, and lead to greater patient involvement in treatment selection in partnership with their treating physician.

\section{CONCLUSIONS}

This study provides insight into treatment selection by physicians and patients by measuring stated and derived preferences for attributes of treatments for both moderate and severe psoriasis. A greater understanding of attribute prioritization during treatment selection for both stakeholders may improve the quality and frequency of shared decision-making. The holistic and comprehensive presentation of information on the attributes of a given treatment, rather than focusing only on specific attributes in isolation, could enhance patient-centered decision-making, and potentially reduce bias introduced by physicians' assumptions regarding patient preferences. Comprehensive education regarding treatment attributes may help minimize the influence of subjective biases and facilitate appropriate and patient-centered treatment selection in psoriasis.

\section{ACKNOWLEDGEMENTS}

Janssen Pharmaceuticals funded the study including article processing charges. All named authors meet the International Committee of Medical Journal Editors (ICMJE) criteria for authorship for this manuscript, take responsibility for the integrity of the work as a whole, and have given final approval for the version to be published. All authors had full access to all of the data in this study and take complete responsibility for the integrity of the data and accuracy of the data analysis.

Disclosures. Seina Lee and Steve Fakharzadeh are employees of Janssen Scientific Affairs, LLC and hold Johnson \& Johnson stock. At the time of the study, Matthew Alcusky was a postdoctoral fellow with Thomas Jefferson University and Janssen Scientific Affairs, LLC. This study was funded by a contract with Janssen Scientific Affairs, LLC. Gordon Lau, Gretchen R. Chiu, Nandini Hadker, Aparna Deshpande, Stephen Fleming, and Nicola Vance have nothing to disclose.

Compliance with Ethics Guidelines. All procedures followed were in accordance with the ethical standards of the responsible committee on human experimentation (institutional and national) and with the Helsinki Declaration of 1964, as revised in 2013.

Data Availability. The datasets generated during and/or analyzed during the current study are not publicly available because of potential confidentiality issues but are available from the corresponding author on reasonable request.

Open Access. This article is distributed under the terms of the Creative Commons Attribution-NonCommercial 4.0 International License (http://creativecommons.org/licenses/ by-nc/4.0/), which permits any noncommercial use, distribution, and reproduction in any medium, provided you give appropriate credit to the original author(s) and the source, provide a link to the Creative Commons license, and indicate if changes were made.

\section{REFERENCES}

1. Helmick CG, Lee-Han H, Hirsch SC, Baird TL, Bartlett CL. Prevalence of psoriasis among adults in the U.S. 2003-2006 and 2009-2010 National Health and Nutrition Examination Surveys. Am J Prev Med. 2014;47(1):37-45. 
2. Shbeeb M, Uramoto KM, Gibson LE, O'Fallon WM, Gabriel SE. The epidemiology of psoriatic arthritis in Olmsted County, Minnesota, USA, 1982-1991. J Rheumatol. 2000;27(5):1247-50.

3. Javitz HS, Ward MM, Farber E, Nail L, Vallow SG. The direct cost of care for psoriasis and psoriatic arthritis in the United States. J Am Acad Dermatol. 2002;46(6):850-60.

4. Koo J. Population-based epidemiologic study of psoriasis with emphasis on quality of life assessment. Dermatol Clin. 1996;14(3):485-96.

5. Kurd SK, Gelfand JM. The prevalence of previously diagnosed and undiagnosed psoriasis in US adults: results from NHANES 2003-2004. J Am Acad Dermatol. 2009;60(2):218-24.

6. Langley R, Krueger G, Griffiths C. Psoriasis: epidemiology, clinical features, and quality of life. Ann Rheum Dis. 2005;64(2):ii18-23.

7. Feldman R, Zhao Y, Shi L, Tran MH. Economic and comorbidity burden among patients with moderate-to-severe psoriasis. J Manag Care Spec Pharm. 2015;21(10):874-88.

8. Menter A, Gottlieb A, Feldman SR, et al. Guidelines of Care for the management of psoriasis and psoriatic arthritis: Section 1. Overview of psoriasis and guidelines of care for the treatment of psoriasis with biologics. J Am Acad Dermatol. 2008;58(5):826-50. doi:10.1016/j.jaad.2008.02.039.

9. Schmitt J, Rosumeck S, Thomaschewski G, Sporbeck B, Haufe E, Nast A. Efficacy and safety of systemic treatments for moderate-to-severe psoriasis: meta-analysis of randomized controlled trials. Br J Dermatol. 2014;170:274-303.

10. Papp K, Gottlieb AB, Naldi L, et al. Safety surveillance for Ustekinumab and other psoriasis treatments from the psoriasis longitudinal assessment and registry (PSOLAR). J Drugs Dermatol. 2015;14(7):706-14.

11. Lebwohl M, Kavanaugh A, Armstrong AW, Van Voorhees AS. US perspectives in the management of psoriasis and psoriatic arthritis: patient and physician results from the population-based multinational assessment of psoriasis and psoriatic arthritis (MAPP) survey. Am J Clin Dermatol. 2016;17:87-97.

12. Ashcroft DM, Seston E, Griffiths CE. Trade-offs between the benefits and risks of drug treatment for psoriasis: a discrete choice experiment with U.K. dermatologists. $\mathrm{Br} \mathrm{J}$ Dermatol. 2006;155(6): 1236-41. doi:10.1111/j.1365-2133.2006.07535.x.

13. Bruera E, Willey JS, Palmer JL, Rosales M. Treatment decisions for breast carcinoma: patient preferences and physician perceptions. Cancer. 2002;94: 2076-80.

14. Renzi C, Di Pietro C, Gisondi P, et al. Insufficient knowledge among psoriasis patients can represent a barrier to participation in decision-making. Acta Derm Venereol. 2006;86(6):528-34.

15. Kjellgren KI, Ring L, Lindblad AK, Maroti M, Serup J. To follow dermatological treatment regimenspatients' and providers' views. Acta Derm Venereol. 2004;84:445-50.

16. Harkness J. Patient involvement: a vital principle for patient-centred health care. World Hosp Health Serv. 2005;41(12-6):40-3.

17. Umar N, Schaarschmidt ML, Schmieder A, Peitsch WK, Schollgen I, Terris DD. Matching physicians' treatment recommendations to patients' treatment preferences is associated with improvement in treatment satisfaction. J Eur Acad Dermatol Venereol. 2013;27(6):763-70.

18. Schaarschmidt ML, Schmieder A, Umar N, et al. Patient preferences for psoriasis treatments: process characteristics can outweigh outcome attributes. Arch Dermatol. 2011;147(11):1285-94.

19. Seston EM, Ashcroft DM, Griffiths CEM. Balancing the benefits and risks of drug treatment: a stated-preference, discrete choice experiment with patients with psoriasis. Arch Dermatol. 2007;143(9):1175-9.

20. Hauber AB, Gonzalez JM, Schenkel B, Lofland JH, Martin S. The value of patients of reducing lesion severity in plaque psoriasis. J Dermatol Treat. 2011;22:266-75.

21. Bridges JFP, Hauber AB, Marshall D, et al. Conjoint analysis applications in health-a checklist: a report of the ISPOR Good Research Practices for Conjoint Analysis Task Force. Value Health. 2011;14:403-13.

22. Gonzalez JM, Johnson FR, McAteer H, Posner J, Mughal F. Comparing preferences for outcomes of psoriasis treatments among patients and dermatologists in the U.K.: results from a discrete-choice experiment. Br J Dermatol. 2017;176:777-85. 